\title{
Quantitative Autoradiography
}

National Cancer Institute

\section{Source}

National Cancer Institute. Quantitative Autoradiography. NCI Thesaurus. Code C18639.

Autoradiographic analysis performed in accordance with specified guidelines that will result in a defined correspondence between the intensity of the autoradiographic image and the amount of radioactivity present in the sample. This permits assignment of a value to the amount of radioactive material in the object under study. 